\title{
GIVING EVERY STUDENT A 'VOICE'
}

\author{
THE USE OF AN INTERACTIVE CLASSROOM \\ TECHNOLOGY TO TRACK AND PROMOTE \\ INDIVIDUAL STUDENT LEARNING IN \\ LARGE CLASSES
}

Elisabeth Brenner

\section{INTRODUCTION}

An ideal pedagogy would enable students to construct knowledge through ongoing dialogue with their teacher, as well as allow them time to reflect on and evaluate what they have learned and put new knowledge into context with respect to how it relates to what they already know. In other words, an ideal pedagogy would establish whether recently introduced concepts make sense and have meaning. While this might be possible in a one-to-one tutoring situation, it is obviously difficult to achieve in a large lecture theatre filled with a large number of students, which is currently the reality of many university classrooms. One of the major difficulties in teaching large classes in higher education, then, is to track individual learning as it occurs. For example, while most lecturers pose questions to the class in general during lecture periods, in large classes, many students are too intimidated to attempt an answer. It is also difficult to get all students in a large class to interact meaningfully and to engage with the lecturer, which means that, in large classes, the lecturer is often seen purely as an authority figure, rather than as someone who is facilitating the students' own learning.

This paper reports on the use of an interactive classroom technology, the InterWrite PRS (personal response system), which was introduced into a large second-year Molecular Biosciences class at the University of the Witwatersrand (Wits) School of Molecular and Cell Biology (MCB) in 2007 in an attempt to circumvent the difficulty of teaching to individual needs in classes that had been steadily increasing in size over the previous few years. Specifically, it discusses how this technology may be used within a social constructivist framework to create an environment that supports optimal teaching and learning and enables lecturers to teach, as much as is possible, to the needs of the individuals in a large class.

\section{THE SOCIAL CONSTRUCTIVIST APPROACH TO LEARNING}

At the outset, I would like to state that my stance on learning as a constructive activity is the result of observations made in class over the past thirty years that I have been 


\section{PART TWO • EVIDENCE AND CASE STUDIES OF LARGE-CLASS TEACHING}

teaching in higher education. In contrast to some other learning theories, such as empiricism, which regards knowledge as being derived solely from the internalisation of sensory input from the environment (which is unfortunately what might be presumed by many academics when they subject their students to hours and hours of listening to lectures), constructivism proposes that knowledge is generated by a complex interaction between the learner and the environment. Writing from a social constructivist perspective, Vygotsky (1978) proposes that tools (which are externally oriented) and signs (which have become internally positioned in the mind) can be used to orient human behaviour, and are therefore necessary for learning. Learning thus takes place in individuals as a result of the social interaction between them and the society in which they function, and in relation to the tools they are able to access and the signs they have internalised. Vygotsky illustrates this point by citing the example of a child first pointing at an article and learning what the pointing gesture means from the reaction of its mother.

The above example highlights the role played by feedback in learning and the construction of knowledge. Indeed, feedback has been cited as one of the most crucial underpinnings of successful learning and/or improvement in performance. This is because positive feedback reinforces current performance or behaviour, as it basically signals that it is acceptable for an individual to continue in the same way as before; while negative feedback signals the necessity for an adjustment of behaviour or a change of some aspect of performance (Van Duijvenvoorde, Kanolie, Rombouts, Raijmakers \& Crone 2008). Extensive research about the role of feedback in academic learning has shown that continuous feedback to students is an important strategy for motivating them and for promoting learning (Higgins, Hartley \& Skelton 2002; Hirsch \& Gabriel 1995; Knight 2004; Rust, Price \& O'Donovan 2003; Taras 2001). Butler (1988) notes that the most effective feedback occurs in a dialogue between teacher and student - something that is obviously difficult (if not impossible) to achieve in a large lecture hall, as it is very easy for students to disengage in this situation. It is also not easy for a lecturer to know whether, and to what extent, feedback is required by the individual students in a large class, or whether, once a new concept has been introduced, it has been understood by everyone in the class.

Most lecturers, especially in large classes, tend to ask the class in general whether they have understood a concept, and more often than not the consensus response is affirmative, regardless of the real state of knowledge of the majority of the class. This is because weaker class members are often too intimidated to disclose to the lecturer, or to make their peers aware, that they have not grasped the concepts that have just been taught. The result is that in large classes held in lecture halls the lecturer usually teaches to the stronger students in the class, as they are generally the most vocal. It is often only after a summative assessment that a lecturer becomes aware that a concept has not been understood, or that a student is unable to apply it. This is particularly problematic in the sciences, where the discourse has been described by Bernstein (2000) as being 'vertical' as well as 'hierarchical', which implies the existence of a 
particular developmental trajectory. Alternative strategies used by lecturers to gauge the level of knowledge and understanding of their students during contact periods also present their own difficulties. For example, conscientious teachers often resort to oral questioning during contact periods, both as a means of formative assessment to ascertain the level of understanding of the students present, and to gauge the level at which to pitch their instruction. However, the questions posed to the whole class are again usually answered by the stronger, more confident students, which promotes a false sense of security on the part of the lecturer regarding the grasp by the group as a whole of the material presented. Interactive lectures where each student is asked to attempt to solve a problem posed to the class also pose their own challenges. In this situation, I have observed that many students either do not participate or pretend to participate, waiting instead for the lecturer to eventually provide the solution (presumably so they can note it down with the intention of learning it by rote for future regurgitation), because, even while moving around the lecture hall and engaging with individual students, it is just not possible for the lecturer to monitor the actual level of participation and engagement of every member of a large class. This may have negative consequences, especially in the case of subjects where conceptual knowledge is cumulative and misconceptions and knowledge gaps impact on and restrict future learning.

These circumstances compelled MCB to search for a pedagogy that could circumvent some of the problems inherent in large classes. Specifically, we were looking for something that would indicate to the lecturer the state of understanding and knowledge of individual students in a large class while teaching and learning was in progress. We also wanted to implement a pedagogy that could be used in face-to-face teaching (as opposed to computer-based instruction), in order to promote social interaction, so that students could engage with the lecturer and with one another to enhance their learning.

\section{INTRODUCTION OF THE INTERACTIVE CLASSROOM TECHNOLOGY}

After searching the Internet, contacting agents, and viewing demonstrations of various products that could potentially provide a solution to the difficulty of being pedagogically responsive to the needs of individuals in a large class, an interactive classroom technology, the InterWrite PRS was introduced into a large (150 students) second-year Basic Molecular Biosciences class in 2007. At the time, Basic Molecular Biosciences II was a corequisite course for all major courses offered at the Wits School of Molecular and Cell Biology (MCB) - which meant that all second-year students registered at the School were required to take it - and covered all the basic concepts required for other Molecular Biosciences courses, which made it ideal for the introduction of this system. Another advantage was that the course was taught by one lecturer only for most of the year (from February until the September break), which meant that the students' progress could be monitored by someone who was not only dedicated to tailoring contact periods to their needs in order to promote learning and understanding, but also keen to try out the technology and optimise its use in the classroom. 


\section{PART TWO • EVIDENCE AND CASE STUDIES OF LARGE-CLASS TEACHING}

The InterWrite PRS enables each student in a classroom to respond to a question (or questions) displayed on PowerPoint slides using a personal radio transmitter (or 'clicker'), which transmits their responses to a receiver that is plugged into a USB port in the lecturer's laptop. Once the time limit set on each question has elapsed, the results of all the responses received are projected in a nominated graphical format (for example, a bar graph) for the class to view. This allows the lecturer to see straight away how the class has responded to the question; for example, to see how many individuals have selected each option in a multiple choice question. The lecturer is also able to see exactly when each response is received, follow the cumulated percentage of correct answers as the responses are recorded, and, if necessary, adjust the previously set time period to allow everyone sufficient time to send an answer. ${ }^{1}$ In this way, the lecturer can instantly gauge the knowledge of those students who have responded, as well as the understanding of the class as a whole, and pick up on common misconceptions. This enables the lecturer to address problems as they occur during the learning process, especially if the various answers transmitted are discussed immediately after students are informed of the correct answer. At the same time, by virtue of the fact that students immediately ascertain whether their answers are correct or not, and are informed by the lecturer why a given answer is right or wrong, they receive immediate feedback regarding their understanding, performance, and ability to apply what they have learnt. It is also possible to set up questions in such a way that students are informed whether their responses are correct or not as soon as they are received, and have the opportunity to transmit alternative answers to the same question. This is particularly useful for questions with numerical answers that require calculations, as numerous attempts may be made to recalculate, until the correct answer is obtained.

The clicker effectively gives every student, regardless of the size of the class, a voice to answer every question that is posed to the class. Moreover, as the responses are sent anonymously, weaker students are not intimidated by their more able classmates - they can participate and express opinions without any fear of being embarrassed.

One of the most successful strategies used at MCB has been to encourage discussion between students before answers are transmitted, so that the atmosphere in the classroom is relaxed and promotes collaborative learning. It has been noticed that, under these circumstances, individual students do not feel that they are being judged by the answers they transmit; instead, they are enthusiastic about responding and eagerly wait to establish whether their answer was correct or not. (On the other hand, the software also allows the lecturer to review the responses given by each student after each session in order to identify which students are having difficulty and which concepts need more attention.) However, the main value of the system appears to lie in the anonymity of responses during contact periods, which encourages maximum

The number of responses received is displayed on the on-screen taskbar, as is the number of students who have registered for each session, so that one can see when every individual in the class has transmitted a response. 
participation. Students concur with this observation: in a survey undertaken after the first year of using this technology, they described the clickers as a 'very useful tool', and highlighted their anonymity as one of the chief advantages of the system. They also commented positively on the fact that it provides real-time feedback and promotes engagement and motivation. This is particularly important from a social constructivist perspective, as one of the central tenets of social constructivism is that it is necessary for students to be motivated and engaged for learning to take place.

From the lecturer's point of view, it was also evident that students were engaged and motivated. The collaborative learning atmosphere made it a pleasure to engage with the class: students were much more responsive and asked for more explanations of concepts as they were being taught than in previous years, when clickers had not been in use. Moreover, as biosciences are more easily understood with the aid of visual input, the lecturer had been using PowerPoint presentations in the lecture periods anyway, and it did not take much time to insert a few questions into each presentation, as the software allows questions to be set up within a couple of minutes. In fact, the technology allows the lecturer to formulate questions at will and insert them into a presentation during the contact period. It does, however, take time to review responses after lectures and to design follow-up lectures around the findings. Yet, good teaching inevitably involves reflection and a flexible or 'agile' approach, rather than a 'ballistic' one, which presumes that previously prepared lecture content is fired at students during contact periods, regardless of their response or understanding (Beatty, Gerace, Leonard \& Dufresne 2006).

\section{INTERACTIVE TECHNOLOGY IN THE CONTEXT OF LEARNING THEORIES}

Various educational theories suggest conditions that are necessary for optimum learning. For instance, empirical investigations have demonstrated that environmental stimulation has to be meaningful in order to provoke a response. For example, cats that had been brought up in a cage with vertical bars showed measurable brain activity when presented with images of vertical lines; on the other hand, cats that had never been caged did not show this reaction (Lawson 2003). This implies that the images of vertical bars only had meaning for the cats that had experienced vertical bars previously, which points to learning taking place in interaction with the environment (image of vertical bars) and could be related to some previous knowledge of this aspect of the environment.

The abovementioned experiment supports the constructivist theory of learning, which (besides viewing knowledge as being constructed in the mind and requiring the active participation of learners) supposes that a stimulus cannot result in learning unless some prior mental structure exists to allow its assimilation - in other words, prior knowledge affects subsequent learning. Based on my personal teaching experience, it is apparent that students understand new concepts better if they are introduced in terms of what is already known, and especially if they can be linked to an aspect of 
everyday knowledge, which places them in context. This is indicative of the presence of internalised signs (see Vygotsky 1978) in students' minds. And although it appears that the learning process per se does not necessarily occur consciously, for pedagogical purposes, lecturers need to establish what prior knowledge and misconceptions students bring to class with them, and to be aware that students' prior experiences shape their conceptual understanding and interpretation of observations, as this will enable them (lecturers) to provide the correct tools for learning.

Using traditional teaching methods, is obviously extremely difficult to assess the level of knowledge of each individual student in a large class, or to ascertain what mental model each individual has of previously acquired concepts. It is equally difficult to determine what prior experience each student in the class has, or what misconceptions they arrive with prior to the introduction of a new concept. However, these challenges may be circumvented by means of the interactive classroom technology, which, via the radio transmitters and carefully designed questions, provides a mechanism for gauging students' learning and knowledge at any given time in a particular subject area. For instance, in the example shown (Figure 5.1), it is evident that forty per cent of the class could not correctly interpret this graphic representation of a chromatographic elution profile, as they thought that it was the height of the peak, rather than the area

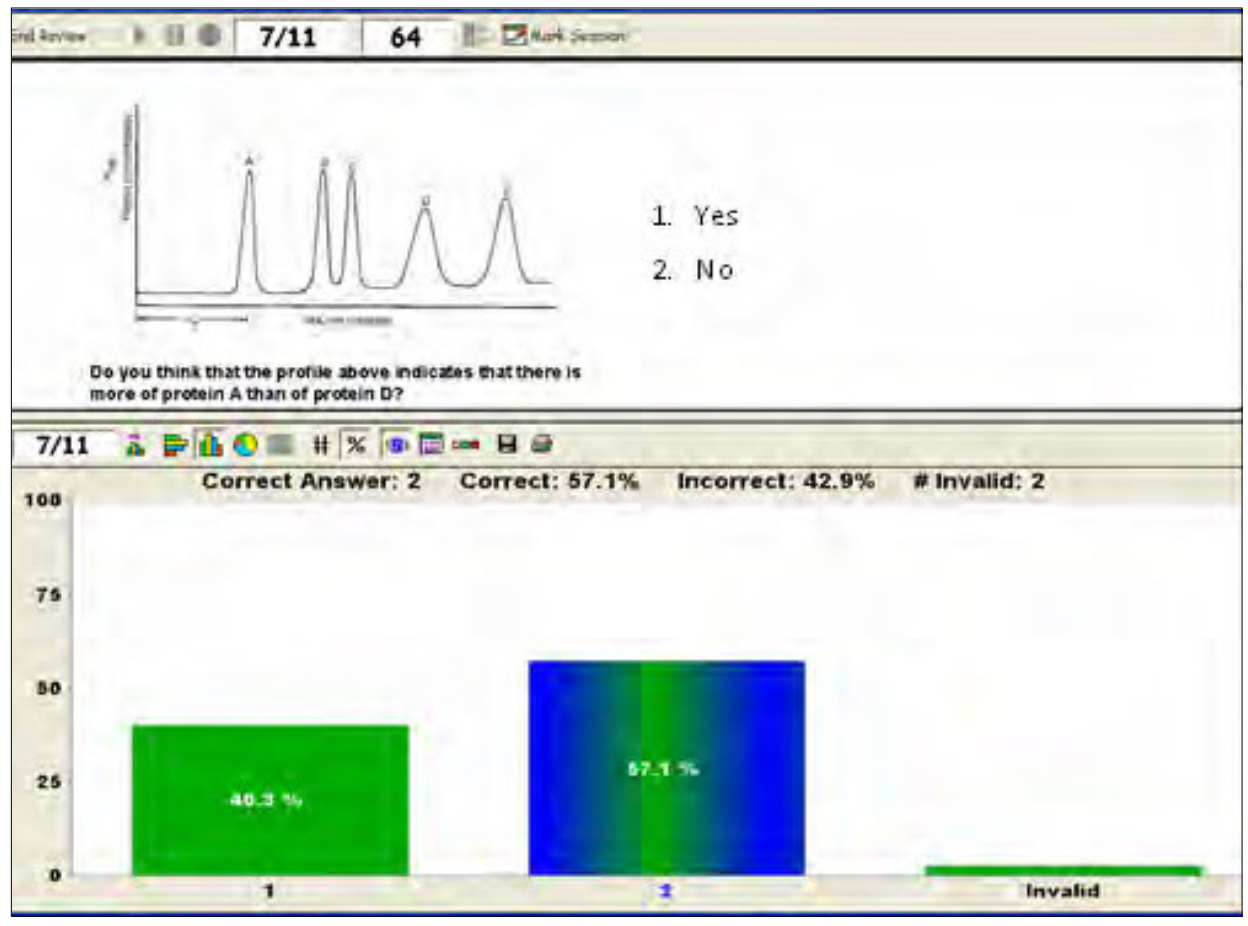

FIGURE 5.1 Example of a clicker question designed to establish students' conceptual understanding of a chromatographic elution profile 
under the curve, that indicates the amount of a substance. This general conceptual misunderstanding would impact on subsequent learning and the interpretation of laboratory results, and discovering it by means of this clicker question was important, as it enabled the lecturer to address the problem. (Surveys also indicated that students were appreciative of the fact that misconceptions could be timeously diagnosed and removed.)

In another example, the clicker system revealed a shortcoming in previous learning that impeded students' ability to perform certain mathematical operations that are important in molecular biology. In the course of their daily activities, molecular bioscientists have to be able to, among other things, prepare solutions; calculate the concentrations of components in solutions; carry out dilutions of stock solutions; adjust concentrations and volumes to suit experimental conditions; construct and use calibration curves; prepare buffers; and interpret differences in the magnitude of spectrophotometric and other measurements. All these operations require the ability to carry out elementary mathematical operations, but are underpinned by the concept of proportionality and an ability to apply proportional reasoning. In light of their background preparatory courses, it would have been reasonable for a lecturer to assume that students enrolled in the Basic Molecular Biosciences II class should be able to perform a simple calculation involving proportion. However, as Figure 5.2 shows, more than half of the

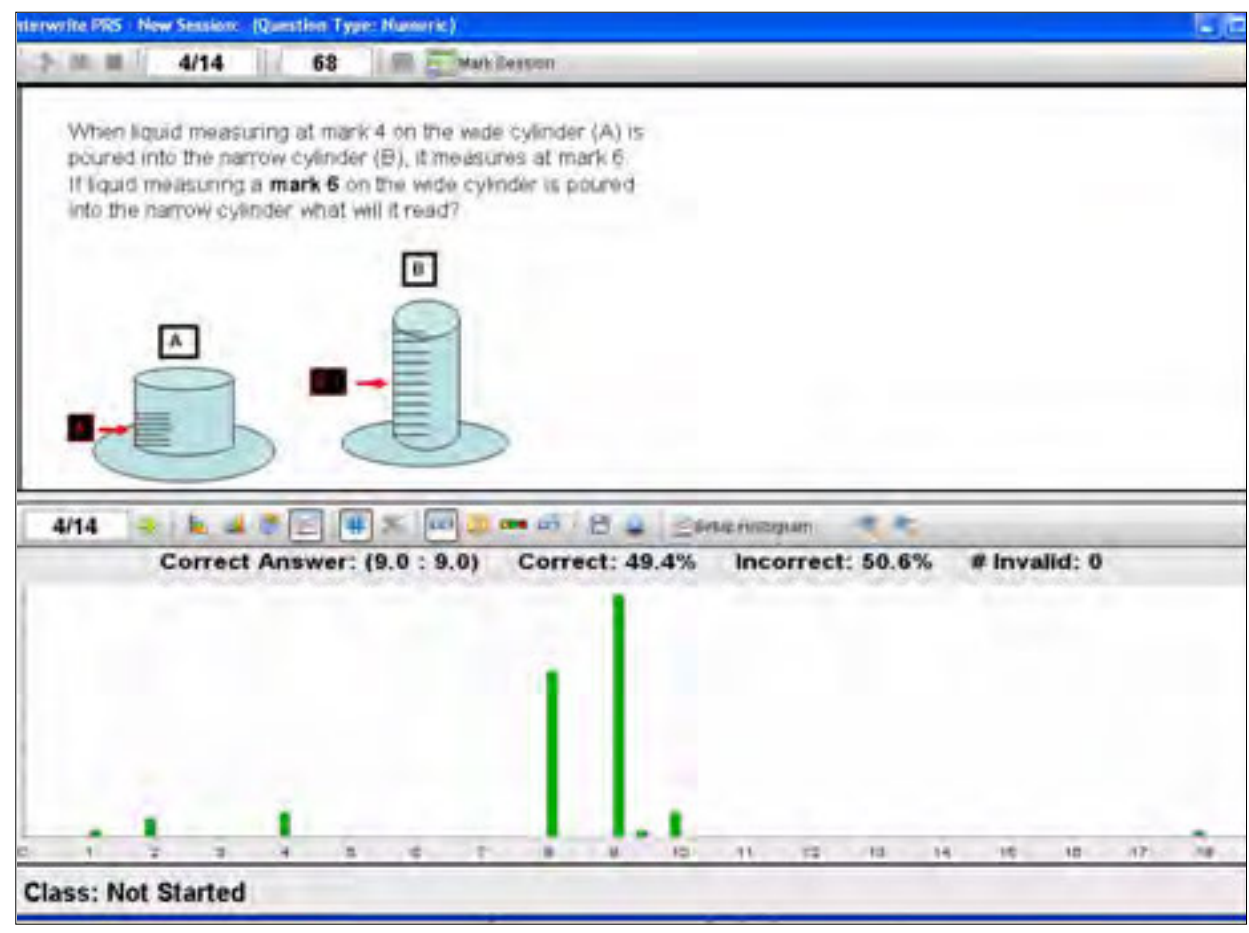

FIGURE 5.2 Example of a clicker question designed to ascertain whether students are able to apply proportional reasoning in a relatively simple problem 


\section{PART TWO • EVIDENCE AND CASE STUDIES OF LARGE-CLASS TEACHING}

students were unable to do so in this instance. This was an important insight, because many lecturers of even more advanced classes had previously felt quite helpless in the face of the inability of many of their students to perform certain operations (such as using the Henderson-Hasselbalch equation to calculate the concentration of the components in a buffer). As these types of operations are also underpinned by the ability to apply proportional reasoning, the results of this clicker question identified the source of the problem.

A major tenet of Vygotsky's constructivist learning theory is that learning occurs "in the zone of proximal development" - the space between what a learner is able to do independently and what she/he is capable of doing with assistance from an instructor or someone else who has already mastered the task: "The zone of proximal development defines those functions that have not yet matured, but are in the process of maturation, functions that will mature tomorrow but are currently in an embryonic state" (Vygotsky 1978:86). Once tasks belonging to the zone of proximal development (ZPD) become familiar, the 'knowledge' learned is said to have been internalised, so that the form and content of knowing are no longer the same as they were at the level of mediation. However, in order to teach in the ZPD, one would have to establish the existing knowledge level of each individual in the group, so that the introduction of new content may be pitched at the appropriate level. In this regard, too, the interactive PRS offers assistance, because it allows the lecturer to ask targeted questions in order to establish the level of all the students in the class.

It is, however, important to note that the technology per se is not a magic bullet. In order to be effective, it must be used within a pedagogically sound framework, and the design of questions is paramount in this regard. Also important is the timing of the various types of questions within a given contact period. For example, it is clearly important that questions aimed at establishing the misconceptions held by students are put to the class before a new concept is introduced, or before expanding on a previously acquired concept. Figure 5.3 shows the results of a clicker question designed to test whether students taking the Basic Molecular Biosciences II course were able to interconvert between different units, as one would reasonably expect, considering that they had all passed Chemistry 1, which is a prerequisite for Basic Molecular Biosciences II. However, the results showed that a significant proportion of the class experienced difficulty with interconversion between units (more than one-third of the students answered incorrectly). As the lecturer had posed the question prior to expanding on this area, she was able to address the problem before continuing; whereas otherwise, she would remain ignorant of the students' lack of interconversion skills and the problem would persist and negatively impact on further learning and performance. 


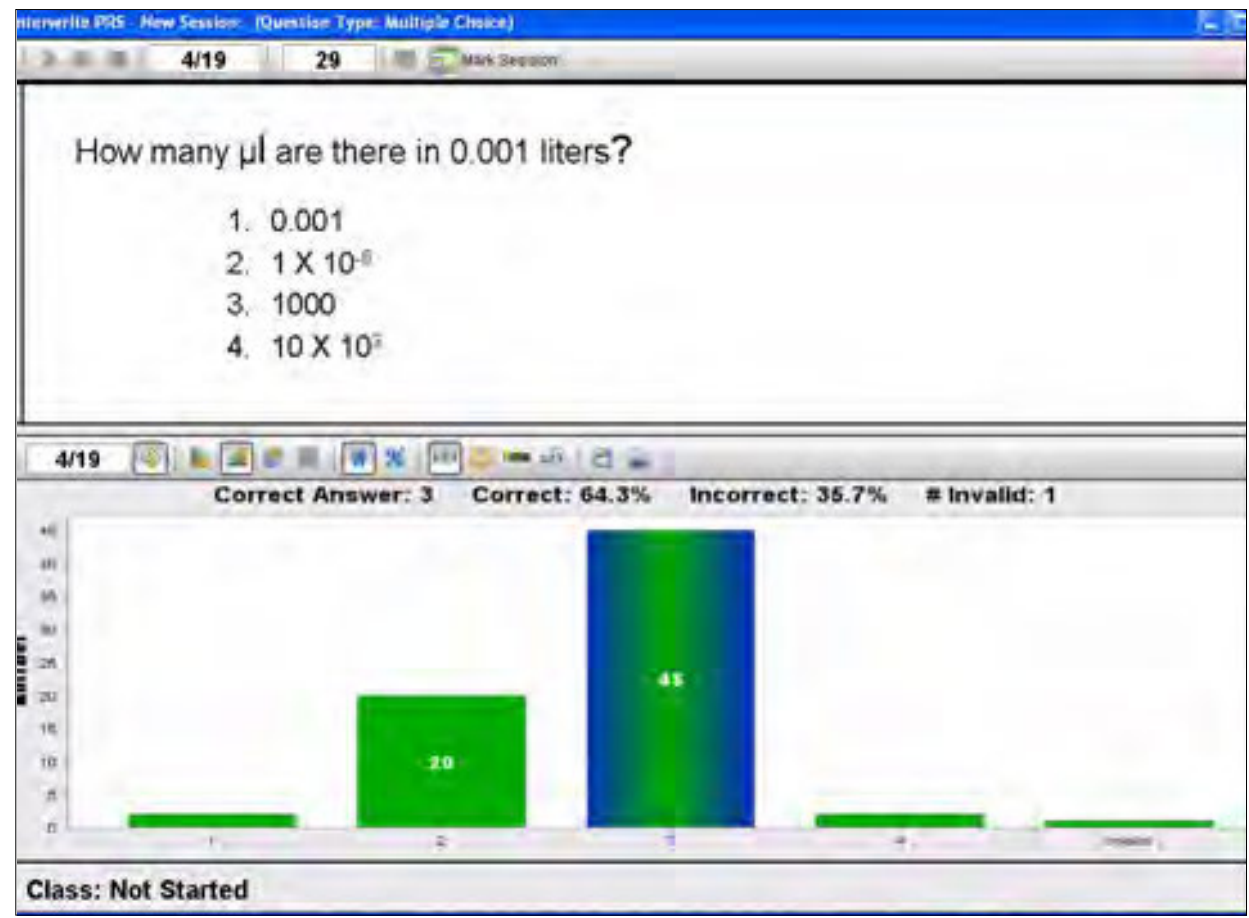

FIGURE 5.3 Example of a clicker question designed to establish whether students in a secondyear Basic Molecular Biosciences class are able to interconvert between units

In terms of questions, the InterWrite PRS allows the lecturer to devise multiple choice, true/false and numerical questions, and to take surveys. Surveys are very useful, because they not only allow the lecturer to gain insight into individual student opinions regarding contentious issues, but also require students to make predictions and answer open-ended questions, which promotes discussion, engagement and critical thinking in the classroom. In fact, Beatty and colleagues (2006), who have been researching interactive classroom technologies since 1993, argue that this aspect constitutes the main benefit of such technology, particularly as it relates to metacognition. When students are encouraged to discuss possible answers among themselves prior to submitting them, and the lecturer initiates a general class discussion after the answers have been received, the technology opens the way for open and guided peer instruction. In this way, the classroom becomes an ideal environment for learning through social interaction with one's peers or other, more knowledgeable, individuals, which ultimately produces better learning outcomes than individual learning (Johnson, Johnson \& Smith 1998). This is also true from my experience with PRS: weaker students - who have the most to gain from collaborative learning - like to discuss questions and possible answers in small groups before submitting their answers, whereas stronger students tend to submit their answers before asking their colleagues which answers they 


\section{PART TWO • EVIDENCE AND CASE STUDIES OF LARGE-CLASS TEACHING}

gave. Hence, in addition to the anonymity provided by the clicker technology, it also facilitates collaboration between students, which relieves the pressure on individuals who might feel too intimidated to attempt to answer a question on their own and would certainly never have done so verbally in a large classroom.

\section{THE IMPACT OF TECHNOLOGY ON POWER RELATIONSHIPS IN LARGE CLASSES}

The introduction of the clicker system into the Basic Molecular Biosciences II course brought about another noteworthy effect, namely a shift in power relationships in the classroom. In her review of the socio-cultural aspects of assessment, Gipps (1999) comments on the power relationships originating from various assessment practices. PRS technology provides a means for implementing ongoing diagnostic or formative assessment, but it is important that students interrogate the feedback they receive during the process. When used optimally, feedback is not limited to noting whether a student has answered a question correctly or not; it also gives the lecturer the opportunity to explain the reasoning behind correct answers and to ask students to verbally justify their own answers. Multiple choice questions, for instance, are often criticised for not giving students an opportunity to explain the reasoning behind their choice of answer. However, in this situation, when students are asked to provide the reasoning behind their choice in a multiple choice, or true/false question, they also get the opportunity to improve their argumentation skills. Used in this way, the technology provides a mechanism for getting students to engage with the material being taught in a way that should lead to deep, rather than surface, learning. This stands in sharp contrast to the more usual situation in large classes, where the lecturer will continue to deliver content, regardless of the individual level of learning of each student in the class.

It is also evident that using this technology in large classes has resulted in lectures being student- rather than lecturer-driven. This means that students (regardless of the class size) are placed at the centre of instruction, so that contact periods become focused on learning, rather than teaching - it would indeed be difficult for a lecturer to deliver a prepared lecture when faced with evidence that many students in the class have either not been following, or did not have sufficient conceptual understanding to engage with new material when it was introduced. One argument against the system, proffered by lecturers who have not used it, is that clicker questions take up lecture time, which makes it impossible to cover all content and finish the syllabus on time. However, in our experience at MCB, students quickly accept that they have to take responsibility for their own learning, and that the lecturer is not there simply to provide all the facts (which may be obtained from textbooks and other literature), but rather to help them establish links and promote conceptual understanding. Once they understand this, students tend to take responsibility for learning content details on their own, which leaves the lecturer free to use lecture time to make sure that they have grasped the necessary concepts and to help them make links between different aspects in order to encourage deep learning. 
Finally, the clicker system has also resulted in a redistribution of power between high achievers and weaker students. Previously, it was obvious that the stronger individuals in the class would get frustrated if a lecturer took time out from a lecture to re-explain a concept after the class as a whole had indicated that they understood it when asked. However, once these stronger students can literally see (via the projected graphical display) that many students in the class are in fact still struggling with a concept, they became far more tolerant, and in some situations are even prepared to move seats to work with the weaker students in small groups in order to assist them to achieve conceptual understanding. This encourages stronger students to assume the role of teacher in some instances, and some have indicated anecdotally that helping others also improves their own conceptual understanding, while weaker students indicate that they often find it easier to gain conceptual understanding from a peer, rather than relying only on the lecturer.

\section{LEARNING THEORIES THAT SUPPORT CLASSROOM QUESTIONING}

From the evidence presented thus far, it is evident that PRS interactive classroom technology is in line with the social constructivist view of learning. However, it is worth exploring other learning theories to see whether they also support a pedagogy focused on the lecturer's ability to pose questions and provide immediate feedback to individuals in a large class.

Piaget subscribed to the view that "learning is not spontaneous, but is provoked by situations", and described the essence or basis of knowledge as an operation, or a "set of actions modifying or transforming an object" (Piaget 1964:8). This operation enables the learner to internalise and thus understand the structure of the transformation (operations are always linked to other operations, so that they form part of a structure). Piaget described four developmental 'operational structures' of knowledge acquisition 'pre-verbal', 'pre-operational', 'concrete operational' and 'hypothetic-deductive' - and suggested that individuals' progress through these structures depends on maturation, experience, social transmission, and finally equilibration. His theory of learning hinges on the notion that learners are active: when presented with something that disturbs their state of knowledge (resulting in what he terms 'disequilibrium'), they will react in a compensatory way to regain their 'equilibrium' through a self-regulatory process. Selfregulation implies that the learner will eliminate contradictions and conflicts during the process of attaining equilibrium. Once again, viewed from Piaget's perspective of constructivism, it is evident that the logic inherent in the learning process cannot be achieved through physical experience or external reinforcement, but involves inward reflection and transient self-regulatory deductions, where the learner readjusts his/ her equilibrium to modify existing ways of thinking and accommodate new ideas or ways of thinking, and in the process reconcile them with existing knowledge and thinking. In this view of learning, equilibrium is achieved when a learner who has become dissatisfied with a previous way of thinking makes the necessary adjustments 
to eliminate the sources of conflict and dissatisfaction. Piaget therefore views learning as a process of constructing new, more complex knowledge as a result of a conflict with ideas already assimilated.

One way of provoking disequilibrium in an individual is through the use of questioning: if an incorrect answer is offered, the learner is forced to examine how the correct answer conflicts with his/her assimilated ideas. This is the basis of formative assessment or 'assessment for learning', where assessment is integrated into teaching so as to promote quality assurance (Black \& Wiliam 1998; Leahy, Christine, Thompson \& Wiliam 2005). Shepard (2000) explains that assessment plays a role in linking curriculum and constructivist learning theories in a learning culture. Thus, in a socialconstructivist approach to learning, assessment practices are directly connected to the process of instruction.

Black and Wiliam (1998:139) describe formative assessment as being at "the heart of good teaching". They explain that, in order for assessment to be meaningful, the results must be used to modify teaching. However, most written formative assessments have to be marked. By the time this has been done, new content is often already being dealt with - and there is very little evidence to suggest that lecturers will actually go back and modify their planning and teaching schedule. This is particularly true of the teaching and learning situation in large classes. Lecturers are often discouraged at the thought of setting and marking assignments and tests for large numbers of students; moreover, the delay in receiving their marked assignments back from lecturers means that students do not get the immediate feedback required to provoke disequilibrium and hence promote optimal learning, as per Piaget's theory. Interactive classroom technology addresses both these challenges: it gives lecturers real-time feedback about students' learning, thus affording them the opportunity to be immediately pedagogically responsive; and students can also instantaneously see whether they have developed sufficient conceptual understanding or are able to apply what they have learned during contact periods, without having to wait (sometimes for fairly lengthy periods) to receive this information.

In terms of question design, Beatty et al (who have used interactive classroom technology extensively in higher education to teach physics courses to large classes) suggest that every question asked using this technology should be designed to encompass "content, process and metacognition" (2006:31). The technology may even be used to encourage students to reflect on their own learning. By way of illustration, students in the Basic Molecular Biosciences II class were asked to indicate whether they were able to draw a peptide after they had received instruction on how to do so. Thus the lecturer was able to ascertain how many students had grasped the concept, while the students were forced to reflect on whether they were competent in this content area. If they had not been asked to do so, many students might have assumed that they would be able to draw a peptide at a later stage, after studying the section. However, if they 
were not able to do it immediately after being shown exactly what to do, it is unlikely that they would be able to do so after a lapse of time.

Beatty and colleagues (2006) also stress that interactive classroom technology will deliver the most value if it is used within the framework of a sound educational theory. In this respect, too, carefully designed questions may be used to promote deep learning. On Bloom's taxonomic scale, it is relatively easy to design questions that require conceptual understanding, evaluation and analysis, so that deep learning is promoted. Moreover, students appear to intuit that deep learning is required to master the subject when such questions are posed to them. This element of metacognition discourages surface learning, thus circumventing the difficulty of trying to convey to all the students in a large class what is necessary for successful and deep learning in a particular discourse.

\section{EVIDENCE IN SUPPORT OF THE USE OF CLICKER TECHNOLOGY}

Our initial experience with the interactive classroom technology in 2007 was very positive. A survey indicated that students enjoyed using it and felt that it helped them to learn. It was also evident that student engagement in the classroom had improved. In addition, the average mark in the first formal summative assessment of the year, which covered material that students traditionally struggled to grasp, improved from fortyseven per cent in 2006 to sixty-two per cent 2007 (an improvement of fifteen per cent); and it remained around that level in 2008 (sixty-five per cent) and 2009 (sixty-one per cent). In the absence of a formal controlled study, one cannot state conclusively that this was due to the introduction of the PRS interactive classroom technology. Yet, the course had been taught by the same lecturer since 2004, and as this lecturer also taught most of the course, there was no impact of other lecturers' teaching. The lecturer had the impression that the system had enhanced the classroom environment and felt that it had promoted learning in the large lecture hall.

Due to these positive results, in 2010 the use of interactive classroom technology was extended to the first-year Introductory Life Sciences course, which had 520 registered students that year. Initially, not every lecturer in the two schools (MCB and the School of Animal, Plant and Environmental Sciences (APES)) that share the teaching load of the course used the technology, but at every meeting with class representatives, the students requested that it be used by all the lecturers teaching the course. As a result, from 2011 onwards, almost every lecturer involved in the Introductory Life Sciences I course has been using the technology to teach classes. In addition, a number of lecturers teaching the core courses (with approximately 200 registered students) in the new second-year MCB curriculum now use this technology as well, and find that it promotes engagement and learning. This is interesting, because it suggests that the initial positive assessment of the technology was well founded, and not just the subjective impression of the individual lecturer who first implemented it. 


\section{PART TWO • EVIDENCE AND CASE STUDIES OF LARGE-CLASS TEACHING}

An additional advantage of the system is that the software allows lecturers to review the performance of the class as a whole and of each individual in the class after a contact period. This has tremendous advantages, as it enables lecturers to plan their teaching accordingly - something that is normally particularly difficult to do when one is dealing with large numbers of students. The software also allows lecturers to generate individual reports for each student, which enables them to track the students' progress as the course progresses and to identify the strong and weak areas of individual students - again, something that would be impossible to do in a large class without this technology. In addition, it must be emphasised that this feature has not deterred students from participating during lectures, as their responses are anonymous and it would be difficult (although not impossible) for a lecturer of a large class to identify who had sent a particular response during a contact period. In fact, students have indicated that they appreciate the fact that the technology allows them to track their progress and take responsibility for their own learning.

Recently published studies (Crossgrove \& Curran 2008; Dangel \& Wang 2008; FitzPatrick, Finn \& Campisi 2011) corroborate our findings at MCB regarding the use of the clicker system. For example, in a study among students in two nonmajor, first-year biology classes (87 and 107 students, respectively) and a secondyear (46 students) genetics major class at the University of Wisconsin-Whitewater, Crossgrove and Curren (2008) found that students in both the non-major, firstyear biology course and the second-year genetics major course viewed the use of clickers in a positive light. Students at both levels expressed the opinion that the use of clickers in class had helped them to understand concepts and had increased class participation and interaction between students in the classroom. The genetics majors particularly valued the instant feedback; the fact that they were made aware that there were others in the class that did not understand concepts either; and the fact that the clickers had stimulated class discussion. The first-year students appreciated the anonymity afforded by the clickers when participating in class, and found them fun to use. An initial comparative analysis (after one year of clicker use by the authors) of the examination performance in sections that had been taught with the aid of clickers and sections that did not employ it indicated that there was no significant difference. However, when clickers were used by instructors who were experienced at using the technology, and when the questions asked in class were aimed at the higher cognitive levels (comprehension, application and analysis) of Bloom's Taxonomy (1956), there was a significant difference in examination performance, with students performing significantly better on questions asked on sections that had been taught using clickers, regardless of the level of question asked in the examination.

The study by Crossgrove and Curren (2008) confirms much of what has been said in this chapter, particularly that, if used effectively, interactive technology can promote deep learning and improve performance in summative assessments. In their review of the literature pertaining to the use of student response systems, Dangel and Wang 
(2008) note that although most studies indicate that the use of these systems increases class participation, a general improvement in examination results was less evident (however, they also stress that most studies published in this field do not have sufficient controls). This notwithstanding, the use of such interactive classroom systems has never been demonstrated to decrease the level of performance in summative assessments.

\section{CONCLUSION: GIVING EVERY STUDENT A VOICE}

In conclusion, interactive classroom technology has been successfully implemented in a number of courses taught at the Wits School of Molecular and Cell Biology. From the initial introduction into a large class in 2007, its use has been expanded recently, and the pedagogy has also been adopted by many other lecturers of large classes. This is due largely to the demand from students, who have indicated that they enjoy using the technology during contact periods and that it has helped them to engage with material in class - something that is not always easy to do when they are often faceless and shy individuals in a sea of other students. It is also evident that this pedagogy is supported by educational theory and is aligned with a constructivist view of learning. I have demonstrated here that effective implementation of this technology results in even very large classes becoming student-centred and focused on learning; in particular, I would like to emphasise that interactive classroom technology can be used to promote critical engagement during contact periods. In light of our experience with the clicker system, we plan to continue using interactive technology in future, and are hoping to expand it by developing software that can accommodate individual text-based answers to questions. This means that students will be able to generate answers that will allow them to participate at the highest cognitive level, rather than merely select a response from a set of possible answers. However, even at this stage, this technology has proved to be a powerful tool for providing individual students with a voice in face-to-face, large-class learning and teaching. 